\title{
Did NDEs Play a Seminal Role in the Formulation of Einstein's Theory of Relativity?
}

To the Editor:

The most important scientific revolution of the 20th century was Albert Einstein's theory of relativity. There is clear evidence that neardeath experiences (NDEs) not only contributed to but actually were seminal in the development of Einstein's ideas that eventually led to his discovery of the theory of relativity.

Albert von St. Gallen Heim was a distinguished Zurich professor of geology in the late 19th and early 20th century. Heim had fallen while climbing in the Alps and experienced an NDE. Following his own experience, over a 25 year period he collected numerous similar accounts from people who had fallen or had similar accidents. He presented his findings before the Uto Section of the Swiss Alpine Club in February, 1892, and published them in German that same year. In so doing, Heim became the first person in modern history to publish a collection of what would later be referred to as NDEs. (His paper was later translated into English by Russell Noyes and Roy Kletti [1972].)

Among a number of interesting aspects reported by Heim himself, as well as many people he interviewed, was that as his body fell toward the ground below, "Time became greatly expanded" (Heim, quoted in Noyes and Kletti, 1972, p. 47). Said slightly differently, what Heim discovered was that people often reported that as they fell from a great height, time seemed to slow down or stop completely.

This is supported by modern research into NDEs. Kenneth Ring (1980) found that when asked about their sense of time during an NDE, only 2 percent of respondents experienced it as normal. Six percent said time seemed "extended," and an overwhelming majority, 65 percent, said they experienced no sense of time at all during the episode.

A little known fact is that this same Heim happened to be one of Einstein's professors. Biographer Ronald Clark described Einstein's course work at the Zurich Polytechnic Institute: “To these compulsory subjects Einstein added an odd ragbag of optionals which included not only gnomic projection and exterior ballistics, both of which might have been expected, but also anthropology and the geology of mountains under the famous Albert Heim" (Clark, 1971, p. 54, italics added). Another Einstein biographer, Albrecht Folsing, pointed out that Einstein chose 
to take more than the compulsory number of optionals, and often at times that were not convenient:

All students had to attend at least one class each year outside of their special field.... Einstein in fact enrolled for considerably more of these lectures than the mandatory minimum, covering a wide spectrum of subjects, such as "Man's Prehistory" and "Geology of Mountain Ranges," both given by Albert Heim, who started at seven in the morning and always had a crowded lecture room. (Folsing, 1997, p. 66)

In 1952, two years before his death, Einstein wrote a letter to an Arnold Heim, recalling Albert Heim's lectures as "magical" (Folsing, 1997, p. 66).

Einstein had arrived in Zurich in the autumn of 1895, at the age of 16. He failed his entrance exam on the first try, but passed it the following year and was admitted to the polytechnic school. That would have made him a student of Heim's in the years immediately following Heim's presentation and the publication of his paper. Few professors fail to find some time to discuss areas of personal interest, and it takes little imagination to suggest that Heim may have described these experiences to his students. Einstein may also have taken the time to read Heim's published account of his study, and surely the application of Heim's findings to physics in general would have not been lost on him. As an object hurtles through space, time becomes relative, depending on motion. This raises a fascinating question: Could Heim's accounts of NDEs have first suggested to Einstein that time and space were not fixed and constant, as physicists assumed at the time, but were actually relative to each other?

This idea is central to Einstein's revolutionary insights, described in a series of three papers published in 1905 , just ten years after his arrival in Zurich. Physicist Stephen Hawking explained the impact of Einstein's insights on the field of physics: "[Einstein's theory] required abandoning the idea that there is a universal quantity called time that all clocks measure. Instead, everyone would have his own personal time. The clocks of two people would agree if they were at rest with respect to each other but not if they were moving" (Hawking, 1999, p. 67, italics added).

To this point, my argument rests on a great deal of speculation. But there is another anecdote that appears to nail down the issue rather conclusively, simply because it came directly from Einstein. Asked in a New York Times interview how he came to start work on the theory of relativity, Einstein related the idea to a near-death event he 
had witnessed: "He had been triggered off... by seeing a man falling from a Berlin rooftop. The man had survived with little injury. Einstein had run from his house. The man said that he had not felt the effects of gravity-a pronouncement that led to a new view of the universe" (Clark, 1971, p. 303).

And so we have the direct personal testimony of Einstein himself. The seminal inspiration for his ideas that would soon revolutionize physics came directly from Einstein's impromptu interview with an NDEr. I suggest that hearing this account made Einstein more aware of the significance of Heim's work, which might explain why he chose to take more than the required elective courses from Heim, some of which had little to do with his main field of interest, which was, of course, physics.

Of course, the field of near-death studies has played a major part in what I believe to be the next revolution in science: the understanding that our true nature is not physical, but spiritual. But there is substantial evidence that the experience and study of NDEs have played a seminal role in what has, to this point, been the most important revolution in the physical sciences.

\section{References}

Clark, R. (1971). Einstein: The life and times. New York, NY: Avon.

Folsing, A. (1997). Albert Einstein. New York, NY: Penguin.

Hawking, S. (1999, December). A brief history of relativity. Time, p. 67.

Heim, A. v. St. G. (1892). Notizen über den Tod durch Absturz [Remarks on fatal falls]. Jahrbuch der Schweitzerischen Alpclub [Yearbook of the Swiss Alpine Club], 27, 327-337.

Noyes, R., and Kletti, R. (1972). The experience of dying from falls. Omega, 3, 45-52.

Ring, K. (1980). Life at death: A scientific investigation of the near-death experience. New York, NY: Coward, McCann and Geoghegan.

J. “Joe" Timothy Green, Ph.D. P. O. Box 2788

Capistrano Beach, CA 92624 e-mail: jospeverde@aol.com 